\title{
Effect of transverse speed of the tool on microstructure and mechanical properties in dissimilar butt friction stir welding of al5083-copper sheets
}

\author{
Y. Fotouhi ${ }^{\mathrm{a}}$, S. Rasaee ${ }^{\mathrm{a}^{*}}$, A. Askari ${ }^{\mathrm{b}}$ and H. Bisadi ${ }^{\mathrm{a}}$
}

${ }^{a}$ School of of Mechanical Engineering, Iran University of Science and Technology (IUST), Narmak, 16846-13114, Tehran, Iran ${ }^{b}$ Department of Engineering, Science and Research Branch, Islamic Azad University, Tehran, Iran

\begin{tabular}{|c|c|}
\hline A R T I C L E I N F O & A B S T RACT \\
\hline $\begin{array}{l}\text { Article history: } \\
\text { Received September } 20,2013 \\
\text { Received in Revised form } \\
\text { October, } 14,2013 \\
\text { Accepted } 27 \text { February } 2014 \\
\text { Available online } \\
12 \text { March } 2014 \\
\text { Keywords: } \\
\text { Friction stir welding } \\
\text { Dissimilar Al-Cu joint } \\
\text { Intermetallic compounds } \\
\text { Microstructure }\end{array}$ & $\begin{array}{l}\text { In this paper, butt joining of } \mathrm{A} 15083 \text { to commercially pure copper is investigated by friction stir } \\
\text { welding method. The effects of transverse welding speed of the tool on the mechanical } \\
\text { properties and microstructure of the joint were studied, experimentally. By examining different } \\
\text { circumstances, changes in the joint strength were studied and optimized in term of transverse } \\
\text { speed. Based on the obtained results, welding speed can improve or reduce the joint strength } \\
\text { and an optimum value can be found for the welding speed. Welded Joint that was conducted at } \\
\text { the rotation speed of } 800 \mathrm{RPM} \text { and tool traverse speed of } 60 \mathrm{~mm} \mathrm{~min}{ }^{-1} \text { had the highest tensile } \\
\text { strength (i.e. about } 98 \% \text { of the weak base metal). Intermetallic compounds were formed in the } \\
\text { stir zone and XRD results indicated that } \mathrm{Al}_{4} \mathrm{Cu}_{9} \text { and } \mathrm{Al}_{2} \mathrm{Cu} \text { were the intermetallic compounds in } \\
\text { the stir zone. Micro-cracks formed around the intimatelic particles were observed in the section } \\
\text { of joint. }\end{array}$ \\
\hline
\end{tabular}

\section{Introduction}

Friction stir welding (FSW) is a solid state joining process invented by Thomas and coworkers at the Welding Institute (TWI) of UK in 1991 (Kiss \& Czigány 2012). It is a perfect method to weld materials that are hard to be joined by the conventional fusion welding methods such as high strength aluminum alloys and magnesium. FSW which was used initially to connect high strength aluminum alloys (olegrove \& Shercliff, 2003; Sharma et al., 2012; Sutton et al., 2002) is nowadays used frequently for joining many other alloys such as magnesium (Rajakumar et al., 2013), and steel (Khodir et al., 2012). In recent years, the industrial demands have been widely increased for welding and joining dissimilar materials with higher strength and good mechanical properties. Different

* Corresponding author.

E-mail addresses: srasaee@iust.ac.ir (S. Rasaee) 
properties of the material and formation of brittle intermetallic compounds, which have low melting ability, are the main concerns for obtaining a perfect joint using the conventional welding methods. However, FSW as a solid state joining method is suitable technique for dissimilar materials. Most of previous researches have focused on the welding of dissimilar aluminum alloys in a wide range of thickness (Guo et al., 2014; Jonckheere et al., 2013). Copper and aluminum are widely used in practical and engineering applications and hence high quality of weldments made from these materials is an important problem. These materials are incompatible metals due to their higher affinity at temperatures higher than $120^{\circ} \mathrm{C}$ and producing brittle intermetallics on the interfaces (Ouyang et al., 2006). Copper-aluminum friction stir lap welding has been studied extensively to investigate the mechanical properties of the joint (Abdollah-Zadeh et al., 2008; Bisadi et al., 2012, Xue et al., 2011), microstructure evaluations (Bisadi et al., 2012; Firouzdor \& Kou, 2012) and intermetallic formation (Galvãoi et al., 2013; Xue et al., 2010). However, friction stir butt welding of aluminum to copper has been rarely investigated due to the difficulties of performing these welds.

Previous researches have shown that many parameters such as tool rotation speed, welding speed and offset of the tool can influence the quality of the dissimilar FSW joints. Until now, few studies have been performed on dissimilar FSW copper-aluminum butt-joint (Xue et al., 2011; Fotoohi et al., 2013; Galvão et al., 2012) and many aspects of the process are still unknown. In this paper, dissimilar FSW of A15083-copper butt-joints have been studied experimentally and the effect of welding speed on the quality of welded joint is investigated. The aim of this study is to clarify the effect of this parameter on the mechanical properties and the microstructure of butt dissimilar A15083-copper FSW joints.

\section{Experimental procedures}

Plates of Al5083 and commercially pure copper with thickness of $5 \mathrm{~mm}$, length of $200 \mathrm{~mm}$ and width of $100 \mathrm{~mm}$ were butt-welded in this study. The chemical composition and mechanical properties of the used materials are given in Table 1. The edges and surfaces of the plates were cleaned to remove the oxides and other pollutions. A vertical mill with automatic vertical and horizontal movement ability was used in the process. Since, the location of aluminum and copper on the advancing or retreating side can affect the quality of joint, the aluminum plate was located on the advancing side in this research. The tool was rotated at a constant speed of $800 \mathrm{rpm}$ during the process. Control of the force during welding was not possible due to lack of required equipment and only movement of tool was controlled. Welding process was performed using variable tool traverse speeds in the range of 20-100 $\mathrm{mm} \mathrm{min}^{-1}$. Table 2 presents the rotational and longitudinal speeds of the FSW processes. Each experiment was repeated three times and the results are compared with each other.

Table 1

Chemical and mechanical properties of work pieces

\begin{tabular}{cccccccccccc}
\hline & $\mathrm{Si}$ & $\mathrm{Fe}$ & $\mathrm{Cu}$ & $\mathrm{Mn}$ & $\mathrm{Mg}$ & $\mathrm{Cr}$ & $\mathrm{Zn}$ & $\mathrm{Ti}$ & $\mathrm{Al}$ & Hardness & $\begin{array}{c}\text { Tensile Strength } \\
(\mathrm{MPa})\end{array}$ \\
\hline $5083 \mathrm{Al}$ & 0.4 & 0.4 & 0.1 & 0.5 & 4.5 & 0.2 & 0.2 & 0.1 & balance & 98 (Brinell) & 317 \\
$\mathrm{Cu}$ & - & - & $>99.5$ & - & - & - & - & - & - & 45 (Vickers) & 224 \\
\hline
\end{tabular}

Table 2

Parameters of FSW experiments

\begin{tabular}{ccc}
\hline Test Number & Rotational Speed & Welding Speed \\
\hline $\mathbf{1}$ & $800 \mathrm{rpm}$ & $20 \mathrm{~mm} \mathrm{~min}^{-1}$ \\
$\mathbf{3}$ & $800 \mathrm{rpm}$ & $40 \mathrm{~mm} \mathrm{~min}^{-1}$ \\
$\mathbf{4}$ & $800 \mathrm{rpm}$ & $60 \mathrm{~mm} \mathrm{~min}^{-1}$ \\
\hline
\end{tabular}


A cylindrical tool made of $\mathrm{H} 13$ steel and heat treated (to increase its strength and hardness) was used. The diameter of tool shoulder was $20 \mathrm{~mm}$ with concavity of $6^{\circ}$. In addition, the pin was simple cylindrical and non-threaded having diameter and length of $5 \mathrm{~mm}$ and $4.7 \mathrm{~mm}$, respectively. The tool had $3^{\circ}$ tilt angle for the better performing of the process. In order to prevent lateral movement and bending of the plates during the welding a fixture was designed and manufactured. The fixture and tool geometries are shown in Fig. 1 (a) and (b).

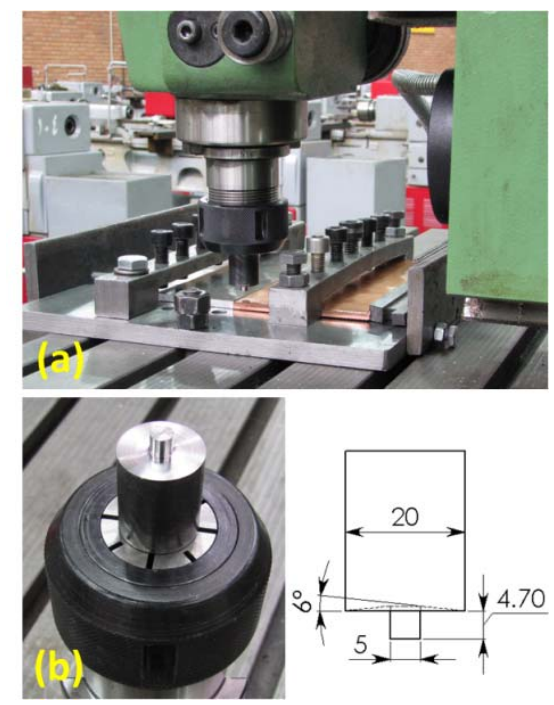

Fig 1. (a) The used fixture; (b) tool and schematic geometry of the used tool for FSW

After welding, a cross-section from each joint was prepared for metallographical analysis. The Poulton's reagent solution was used for etching aluminum and another solution $(60 \% \mathrm{H} 2 \mathrm{O}$ and $40 \%$ HNO3) was used for copper. Then, optical microscope (OM) was used to observe the microstructure of joints. Microstructure characterization and analyses were performed by scanning electron microscopy (SEM), complemented by element distribution analysis maps, X-ray diffraction (XRD) and energy dispersive spectroscopy (EDS). Some tensile tests were also performed to evaluate the strength and mechanical properties of the joints. Tensile specimens according to ASTM-E8M were cut from welded plate perpendicular to the weld line by using water jet such that the joint was in the middle of the specimens. All the tensile tests were performed using SANTAM (STM250) machine with a constant loading rate of $2 \mathrm{~mm} \mathrm{~min}^{-1}$ and for each sample, the maximum tensile load and the position of failure was recorded and detected.

\section{Results and discussion}

The surface and cross-section of the welded specimens are shown in Fig. 2. At traverse speed of $20 \mathrm{~mm} \mathrm{~min}{ }^{-1}$ the surface was rough and a large amount of flashes can be seen on the weld line (especially on the aluminum side). The flashes were thick and almost had no sharp edges. The pasty material which was pushed out of the weld zone is formed these flashes and coarse surface is formed due to stock condition at the contact surface. By increasing the welding speed, the quality of surface was improved and the amount of the flashes were reduced. The specimen manufactured at the welding speed of $60 \mathrm{~mm} \mathrm{~min}^{-1}$ had the best surface quality and as it is seen from Fig. 2, at this welding condition the surface is quite smooth and a little flash is only observed. for welding speeds higher than $60 \mathrm{~mm} \mathrm{~min}^{-1}$ the quality of weld surface is decreased again. Lack of the proper flow of material due to the low ductility is the possible reason for creation of rough surface at such high welding speeds. For specimens welded at speed of $100 \mathrm{~mm} \mathrm{~min}^{-1}$ some particles like chips were observed on the surface of weld showing these particles have been scraped from the surfaces of the plates. Meanwhile at low speeds, the generated heat was not enough to soften the material. Thus for these situations when the shoulder contacts with the workpiece surface, the process occurs similar to 
the chip removal operations that can consequentely create rough surfaces.

There were some voids in the cross-section of the specimens welded with welding speed of $40 \mathrm{~mm}$ $\min ^{-1}$. The cross sections of the welded joints provide information about mixing the $\mathrm{Al}$ and $\mathrm{Cu}$ materials. At low welding speeds, materials mix together almost uniform through the interface and it is seen that more copper is entered to the aluminum side. However, by increasing the welding speed mixing is performed under the influence of the shoulder at the upper side of the weld section and a little mixing occurs at the weld root.

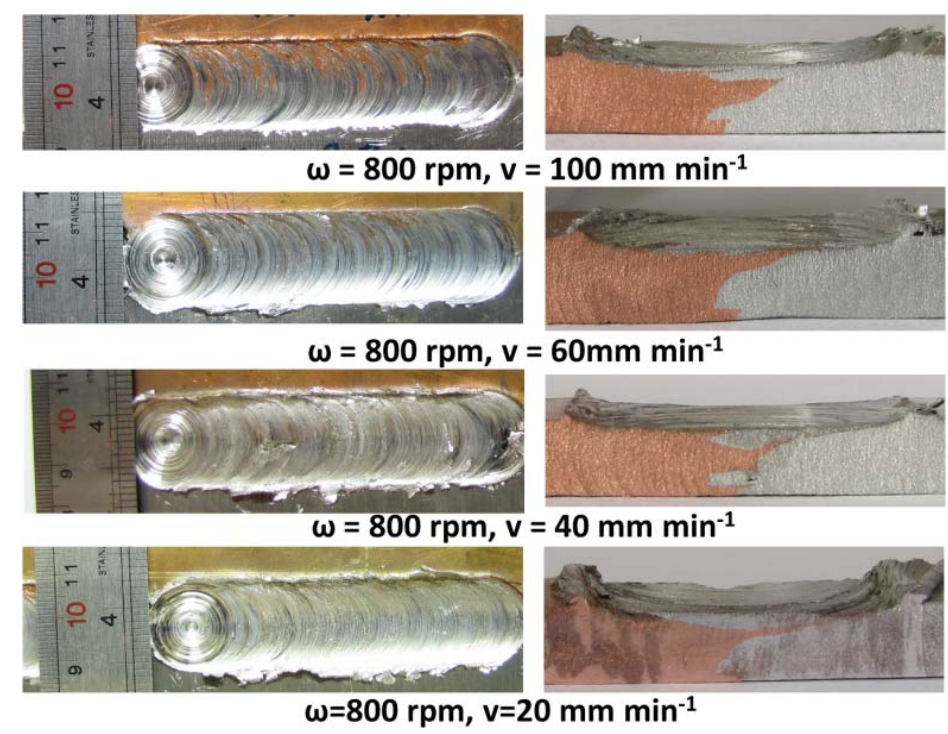

Fig. 2. Surface and cross-sections of the welded Al-Cu specimens

In the middle of cross section of the joint (called stir zone), materials are severely deformed by the rotating motion of the pin and mechanically are mixed. Fig. 3 shows the SEM macroscopic appearance of an $\mathrm{Al}-\mathrm{Cu}$ joint. The dark area formed in the stir zone has clear contrast and different structure and composition from the base materials and is full of particles. Based on the Al-Cu phase diagram, aluminum and copper are incompatible and produce intermetallic components at temperatures higher than $120^{\circ} \mathrm{C}$. Thus, due to rising temperature during the process, intermetallic compounds are formed in the stir zone and in the interface. Hence, the dark area and particles inside the stir zone can be mainly intermetallic compounds that formed during the process.

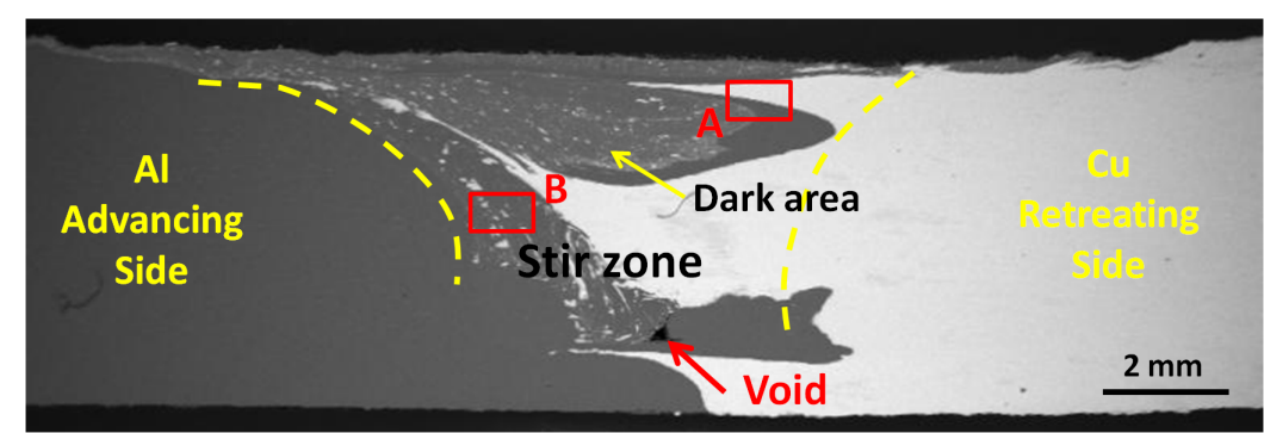

Fig. 3. SEM of the cross-section of the specimen conducted at the tool traverse speed of $40 \mathrm{~mm} \mathrm{~min}^{-1}$

Element distribution analysis maps were performed to determine the composition of particles spread in the stir zone and the corresponding results are shown in Fig. 4. The area shown in Fig. 4(a) for the stir zone contains large bright particles in the dark matrix. Based on the map analysis results, large bright particles are mainly composed of $\mathrm{Cu}$ surrounded by a matrix that mainly was aluminum. Actually, copper particles are cut off from copper plate due to rotation and movement of pin and are spread in aluminum matrix such that an area full of particles in the stir zone is formed. 

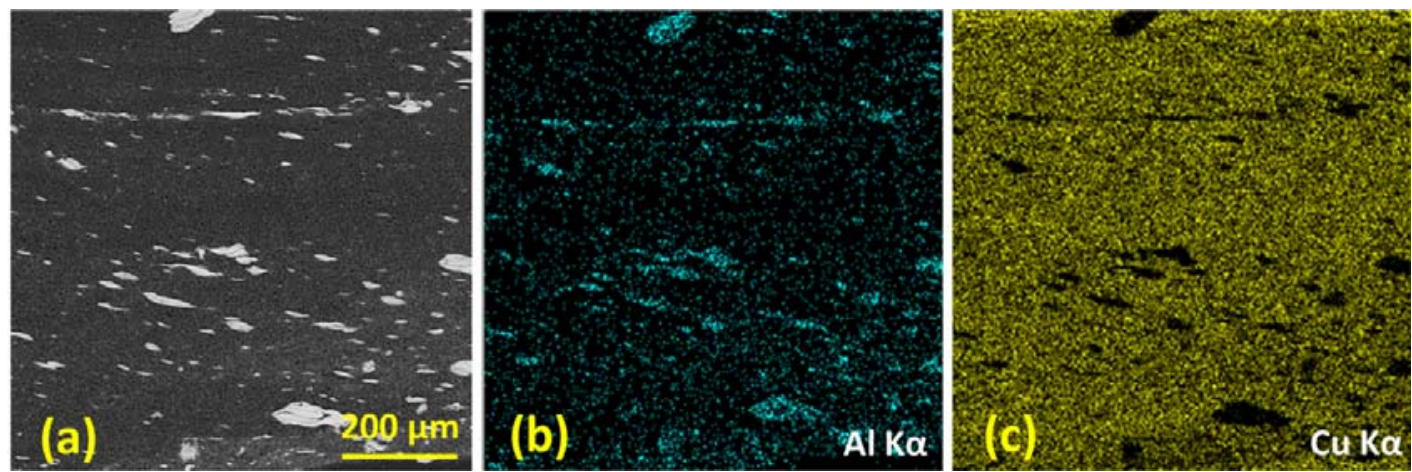

Fig. 4. Element distribution maps of the region in stir zone: (a) magnified view of aregion in stir zone, (b) Al element and (c) Cu element (conducted at the tool traverse speed of $40 \mathrm{~mm} \mathrm{~min}^{-1}$ ).

Magnified view of an area near the interface in the stir zone which located in box A in Fig. 3, is shown in Fig. 5. In this area, three regions can be distinguished with different compositions, based on the energy dispersive spectroscopy (EDS) analysis the bright area that is copper, light gray area that mainly consists of aluminum and copper particles are distributed in it. Also in this Figure the dark gray area with smaller particles (in comparison with the copper particles) show the intermetallic parts.

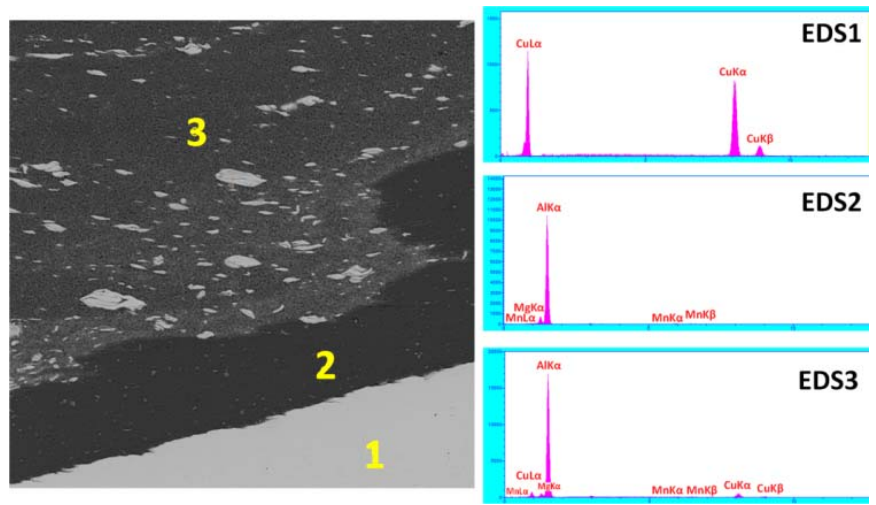

Fig. 5. The energy dispersive spectroscopy (EDS) results of the region in stir zone (located in Box A in Fig. 3) of specimen number 2

To determine the intermetallic compounds that formed during the process, X-ray diffraction analysis (XRD) was performed and XRD results are shown in Fig. 6. Except $\mathrm{Mg}, \mathrm{Al}$ and $\mathrm{Cu}$ that had obvious peaks, intermetallic compounds $\mathrm{Cu}_{9} \mathrm{Al}_{4}$ and $\mathrm{CuAl}_{2}$ were clearly identified. Carefull survey of the morphological structures observed in the SEM images confirms the XRD results as well. By observing the section of joints, it was cleared that the extent of the dark area formed in the stir zone and the amount of particles distributed in the structure near the interface were decreased by increasing the welding speed. Therefore, welding speed has an opposite effect on the formation of intermetallic compounds.

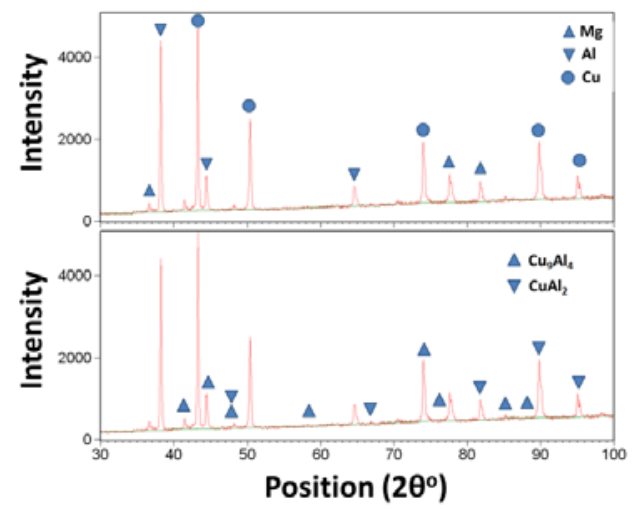

Fig. 6. X-ray diffraction patterns of cross-section of $\mathrm{Al}-\mathrm{Cu}$ joint of specimen number 2 
Fig. 7(a) shows the magnified view of the area located in box B of Fig. 3. A layer structure is observed in the stir zone. This structure looks like the onion ring pattern formed in FSW of some similar aluminum alloys. Layered structure is formed by mechanical mixing of copper and aluminum. At high welding speeds (e.g. $100 \mathrm{~mm} \mathrm{~min}^{-1}$ ) this pattern is clearly observed in the structure as layers of copper surrounded by a dark matrix (Fig.7(b)). The volume of layered structure is reduced by decreasing the welding speed and at low welding speeds, elongated copper particles are observed in the structure instead of layers of copper (Fig.7(c)). At low speeds (e.g. $20 \mathrm{~mm} \mathrm{~min}^{-1}$ ) the temperature is increased and thus the materials are softer and mixed more uniformly. Thus layered structure is decreased at low welding speeds. In addition, Increasing the affinity of the materials at higher temperatures has noticeable influence in reducing the layered structure.
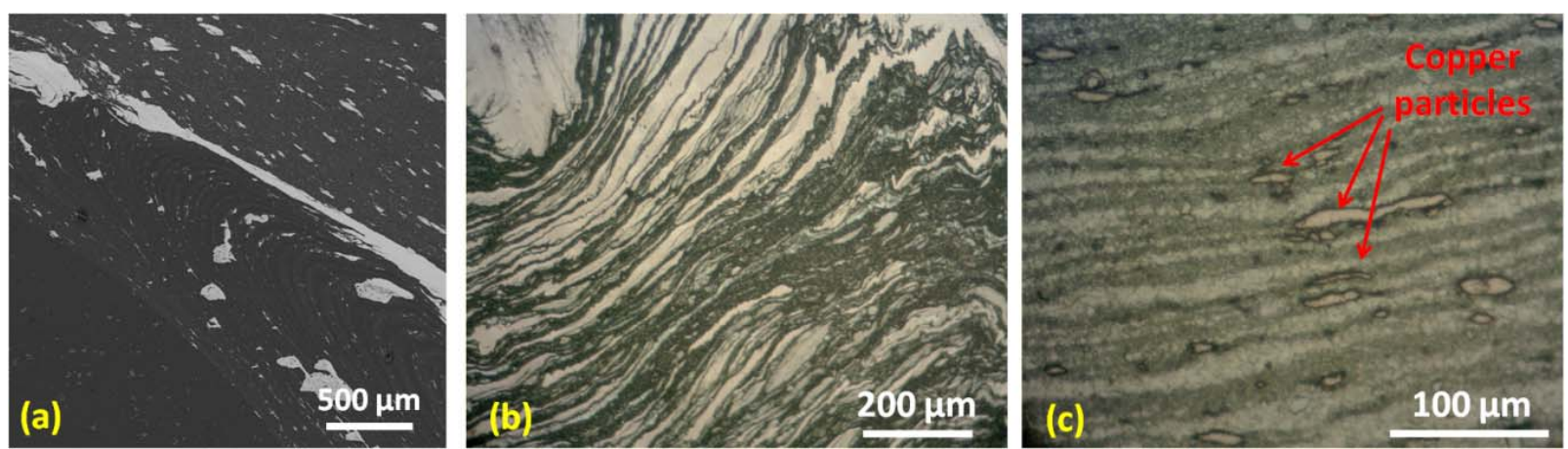

Fig.7. Layered structure formed in the stir zone: a) Magnified view of the region located in box B in Fig. 3; b) Layers of copper surrounded by aluminum matrix in the specimen number 4; c) Elongated copper particles in the specimen number 1

Some defects were observed in the cross-section of specimen numbers 2 and 4 . The defects were formed at the bottom of the joint in the stir zone. Inappropriate mixing of materials due to inadequate heating was the reason of forming defects in the specimen number 4 . Careful observation of the cross-section of specimen number 1 showed the micro-cracks and voids were formed on the surface of the particles dispersed in the matrix or in the boundary between the area of the intermetallic compounds and matrix, as shown in Fig. 8.

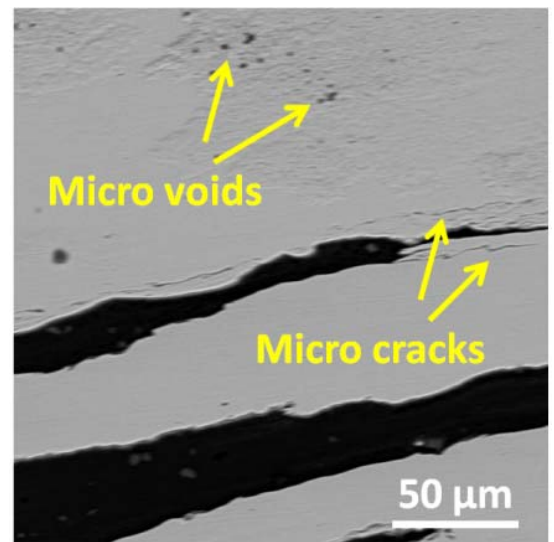

Fig. 8. Micro-cracks and micro-voids observed at the interface of specimen number 1

Table 3 and Fig. 9 show the tensile properties of base metals and the welded joints. The weld joint conducted at the tool traverse speed of $60 \mathrm{~mm} \mathrm{~min}^{-1}$, had the greatest strength (about 98\%) of the strength of weaker material. Strength is increased by increasing the welding speed and at $60 \mathrm{~mm} \mathrm{~min}^{-}$ ${ }^{1}$ the maximum strength was obtained for the Al-Cu joint. However, with further increasing the welding speed, strength is reduced considerably. More creation of intermetallics at low welding speeds that increase the possibility of formation of cracks and defects is the main reason of reducing the joint strength. At high welding speeds, heating was not sufficient, to soften the materials for mixing and performing high quality connection. Thus, lack of proper mixing of materials is the main 
reason of reducing the strength at high welding speeds. Heating at welding speed of $60 \mathrm{~mm} \mathrm{~min}^{-1}$ is sufficient and materials are mixed quite well. Also, the amount of intermetallic compound particles is adequate to compose a metal matrix composite by spreading in structure and improving the strength of FSW joint. The maximum deformations of specimens are presented in Table 3 as well. At speeds less than $60 \mathrm{~mm} \mathrm{~min}^{-1}$, the amount of deformation was increased by increasing the welding speed. However, at higher speeds, increasing the welding speed had a negative effect on the deformation of created bi-material.

\section{Table 3}

Mechanical properties of welded joints

\begin{tabular}{|c|c|c|c|c|}
\hline Specimen number & Transverse speed & Tensile strength (MPa) & Maximum deformation $(\mu \mathrm{m})$ & Fracture location \\
\hline \multirow{2}{*}{1} & \multirow{2}{*}{$20 \mathrm{~mm} \mathrm{~min}^{-1}$} & \multirow{2}{*}{199.3} & \multirow{2}{*}{1950} & Interface \\
\hline & & & & (stir zone) \\
\hline 2 & $40 \mathrm{~mm} \mathrm{~min}^{-1}$ & 205 & 2850 & $\begin{array}{c}\text { Interface } \\
\text { (stir zone) }\end{array}$ \\
\hline \multirow{2}{*}{3} & \multirow{2}{*}{$60 \mathrm{~mm} \mathrm{~min}^{-1}$} & \multirow{2}{*}{225.6} & \multirow{2}{*}{3150} & Interface \\
\hline & & & & (stir zone) \\
\hline 4 & $100 \mathrm{~mm} \mathrm{~min}^{-1}$ & 179.5 & 1300 & $\begin{array}{l}\text { Interface } \\
\text { (stir zone) }\end{array}$ \\
\hline Al5083 & \multirow{2}{*}{ - } & \multirow{2}{*}{317} & & \multirow{2}{*}{ - } \\
\hline Base material & & & & \\
\hline Copper & \multirow{2}{*}{-} & \multirow{2}{*}{231} & & \multirow{2}{*}{-} \\
\hline Base material & & & & \\
\hline
\end{tabular}

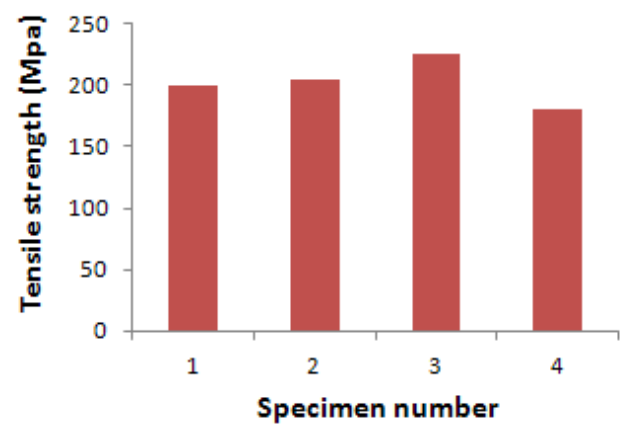

Fig. 9. Average tensile strength obtained for the Al-Cu friction stir welded samples

\section{Conclusions}

Dissimilar plates of copper and Al5083 in butt position were joined by using the FSW. The effects of traverse speed of the tool on the process and the quality of joint were investigated and by changing and by controlling the welding parameters' high strength and high quality joints were achieved. The joint obtained at the tool traverse speed of $60 \mathrm{~mm} \mathrm{~min}^{-1}$ was sound defect-free joint. Also the tensile test results showed that the maximum value of tensile strength was about $225.6 \mathrm{MPa}$ (i.e. about $98 \%$ ) of copper strength. All the specimens failed at the interface in the stir zone with a small elongation before failure. At the cross-section of some specimens, microscopic cracks were observed that normally were formed on the surfaces, and especially at a sharp edges of the intermetallic compounds. At low welding speeds, more cracks were formed due to formation of more intermetallic compounds. There were some defects in samples with no offset at the lower part of the joint and down part of the pin. It was also observed that the tool offset reduces the voids. Inadequate mixing of materials at high welding speeds, and formation of several intemetallic particles at low speeds were the main reasons of reducing the joint strength. The microstructure analysis showed that the created structure contains intermetallic compound that formed during the process in the stir zone. The extent of this region and distribution of intermetallic particles in aluminum matrix, is increased by decreasing the welding speed. The XRD analysis revealed that most of the intermetallic compounds formed in the stir zone were $\mathrm{Al}_{4} \mathrm{Cu}_{9}$ and $\mathrm{Al}_{2} \mathrm{Cu}$. 


\section{References}

Abdollah-Zadeh, A., Saeid, T., \& Sazgari, B. (2008). Microstructural and mechanical properties of friction stir welded aluminum/copper lap joints. Journal of Alloys and Compounds, 460(1), 535538.

Bisadi, H., Tavakoli, A., Tour Sangsaraki, M., \& Tour Sangsaraki, K. (2013). The influences of rotational and welding speeds on microstructures and mechanical properties of friction stir welded A15083 and commercially pure copper sheets lap joints. Materials \& Design, 43, 80-88.

Colegrove, P. A., \& Shercliff, H. R. (2003). Experimental and numerical analysis of aluminium alloy 7075-T7351 friction stir welds. Science and Technology of Welding \& Joining, 8(5), 360-368.

Firouzdor, V., \& Kou, S. (2012). Al-to-Cu Friction Stir Lap Welding. Metallurgical and Materials Transactions A, 43(1), 303-315.

Fotoohi, Y., Rasaee, S., Bisadi, H., \& Zahedi, M. (2013). Effect of friction stir welding parameters on the mechanical properties and microstructure of the dissimilar A15083-copper butt joint. Proceedings of the Institution of Mechanical Engineers, Part L: Journal of Materials Design and Applications, 1464420713499479.

Galvão, I., Verdera, D., Gesto, D., Loureiro, A., \& Rodrigues, D. M. (2013). Influence of aluminium alloy type on dissimilar friction stir lap welding of aluminium to copper. Journal of Materials Processing Technology, 213(11), 1920-1928.

Galvão, I., Oliveira, J. C., Loureiro, A., \& Rodrigues, D. M. (2012). Formation and distribution of brittle structures in friction stir welding of aluminium and copper: Influence of shoulder geometry. Intermetallics, 22, 122-128.

Guo, J. F., Chen, H. C., Sun, C. N., Bi, G., Sun, Z., \& Wei, J. (2014). Friction stir welding of dissimilar materials between AA6061 and AA7075 Al alloys effects of process parameters. Materials \& Design, 56, 185-192.

Jonckheere, C., de Meester, B., Denquin, A., \& Simar, A. (2013). Torque, temperature and hardening precipitation evolution in dissimilar friction stir welds between 6061-T6 and 2014-T6 aluminum alloys. Journal of Materials Processing Technology, 213(6), 826-837.

Khodir, S. A., Morisada, Y., Ueji, R., \&Fujii, H. (2012). Microstructures and mechanical properties evolution during friction stir welding of SK4 high carbon steel alloy. Materials Science and Engineering: A, 558, 572-578.

Kiss, Z., \& Czigány, T. (2012). Microscopic analysys of the morphology of seams in friction stir welded polypropylene. Express Polymer Letters, 6(1).

Rajakumar, S., Balasubramanian, V., \& Razalrose, A. (2013). Friction stir and pulsed current gas metal arc welding of AZ61A magnesium alloy: A comparative study. Materials \& Design, 49, 267-278.

Sharma, C., Dwivedi, D. K., \& Kumar, P. (2012). Effect of welding parameters on microstructure and mechanical properties of friction stir welded joints of AA7039 aluminum alloy. Materials \& Design, 36, 379-390.

Sutton, M. A., Yang, B., Reynolds, A. P., \& Taylor, R. (2002). Microstructural studies of friction stir welds in 2024-T3 aluminum. Materials Science and Engineering: A, 323(1), 160-166.

Ouyang, J., Yarrapareddy, E., \& Kovacevic, R. (2006). Microstructural evolution in the friction stir welded 6061 aluminum alloy (T6-temper condition) to copper. Journal of Materials Processing Technology, 172(1), 110-122.

Xue, P., Xiao, B. L., Ni, D. R., \& Ma, Z. Y. (2010). Enhanced mechanical properties of friction stir welded dissimilar Al-Cu joint by intermetallic compounds. Materials Science and Engineering: A, 527(21), 5723-5727.

Xue, P., Ni, D. R., Wang, D., Xiao, B. L., \& Ma, Z. Y. (2011). Effect of friction stir welding parameters on the microstructure and mechanical properties of the dissimilar $\mathrm{Al}-\mathrm{Cu}$ joints. Materials Science and Engineering: A, 528(13), 4683-4689. 